\section{THE ETIOLOGY OF PUERPERAL FEVER.}

\author{
By ROBERT E. HUNTLEY, M.D., Jarrow-on-Tyne.
}

I AM induced by the letters signed "Obstetricus" and "Junior" to offer a few observations on the above subject.

In the British Medical Journal of August 5th, 1865, I gave details of a number of cases of puerperal fever, which had occurred in my practice a few months previously. It was manifest that the outbreak was in some way associated with me, for it was exclusively confined to my practice, notwithstanding there were four other practitioners in our town. I took all the precautionary measures usually adopted to eradicate the disease, such as baths, changing of clothes, but all to no purpose. I eventually went over to Ireland, and remained there six weeks, after which time I returned, in the confident hope that no chance of my transmitting the disease remained. Nevertheless (and "Obstetricus" should note this), the first two or three cases that I attended showed unmistakable signs of infection, and I was compelled, by the serious consequences, to cease the practice of this branch of the profession for a further period. From my sad experience, then, it was apparent that the obstetrician should relinquish practice during not less than two months. But, when such fearful consequences are involved, it is safer to overestimate rather than underestimate the time; and such was the advice I gave to a midwife who recently lost, to my knowledge, not fewer than four cases within two or three weeks. The frequent ablutions which medical men necessarily undergo make it absurd to suppose that for weeks the materies morbi can be communicated by the hand of the accoucheur; and, when a change of clothing takes place, we may reasonably conclude that all chance of infection from this source is avoided. As further proof of the fallacy of this belief in the production of the disease by this means, I may cite the rarity of our ability to trace pucrperal infection distinctly to these causes.

I left under the charge of my locum tenens several cases when I went from home, yet not a single case occurred among all those he attended in my absence. I find that there is a chimerical fear prevalent among physicians regarding this method of contagion, which oftentimes impels them to act inhumanely. Lately, I was called in to see two cases attended by the midwife abovementioned. I found that the friends had already sought the assistance of medical men, who decidedly refused to attend, because the cases were of this nature. I and my assistant took sharge of these patients (one of whom died after a few days; the other, though still under treatment, is slowly recovering); and I see no reason to regret placing them on our list, as no evil consequences have followed to any of the confinements since attended by us. Hence, and from repeated experiences of this kind, I infer that such a mode of contagion is rare. That it does happen occasionally, I have no doubt; but, with due caution, as by ablution on leaving a patient thus affected, and by allowing some time to elapse between visiting patients where there is a possibility of infection, the risk is exceedingly small. The cases related in the Journal of February 13 th, by Dr. Fenton, would seem to disprove this opinion; but it is by no means certain that the bedclothes in the instances related by him were the source of contagion. I rather incline to the belief that the midwife afforded the fell influence, or was the source from which the poison was derived. Otherwise, burn the bedclothes and set the woman free.

From these considerations and facts, it seemed plain to me then, and I see no reason why I should change my opinion now, that we must look for some other means of communication of the matiries morbi than that generally accepted by the profession; and, guided by the experience thein gained, I advanced the only theory which commended itself to me, viz., that the contagious influence was somehow intimately associated with the person of the obstetrician, and not with his surface or clothing only. It is true that I was unaware of any morbid condition then existing in my own constitution which would be likely to give rise to any morbid exhalation, and fortify me in the belief entertained. Still, it is pussible that, unobservable to myself, there may have been present some defect in the assimilating process, some error in the secretory or excretory systems, which would generate a morbid material capable of producing septicæmia. It may be, however, that the toxic matter is not generated de noz'o in the system; but, being received from external sources in the first instance, becomes propagated by some unknown means. What I seek, however, mainly to establish is, that the clothes theory is untenable. As to whether the obstetrician can communicate this disease without vaginal examination, I have no definite opinion, not being able to call to mind any instance in which it has happened; but, with views such as mine, such an occurrence would appear by no means unlikely, indeed, nearly as likely as if the whole process of delivery had been under the superintendence of the ac- coucheur, i.e., presuming that he had been at any time in close contact with the patient.

It is of vital import that the obstetrician should recognise at the very earliest stage the true character of the malady ; and the points to which, in my opinion, attention ought to be directed, are the various causes from which puerperal fevers originate. These may conveniently be divided into three classes.

r. Those originating in the patient herself, as general unhealth giving rise to inflammation of the uterine and peritoneal structures, or such as spring from intrauterine causes, putrescence of the infant or of the other contents of the uterus.

2. Such as spring from atmospheric influences, and give rise under ordinary circumstances to fevers, as scarlatina, typhoid, and typhus.

3. That lamentable and malignant form mysteriously communicated by the accoucheur.

Cases of the first class are frequently easily diagnosed, though cases will arise from this cause which may baffle the most expert. As regards the second class, a good, and perhaps the only reliable, guide, is the prevalence in the district of fevers of an epidemic nature. I am of opinion, however, that the epidemic or typhoid form of puerperal fever does not always coexist with the prevalence of typhus or typhoid, but that there is some meteorological condition conducive essential to its production. In all these cases, though the materie's morbi may not be identical, yet blood-poisoning is the result, and the symptoms are only modified by the constitutional peculiarities and condition of life of the patient.

It has occurred to my mind that, assuming this theory of the production of puerperal pyæmia by the obstetrician, as asserted by me, to be true, it would be matter for serious thought, whether, in the event of a second outbreak in the practice of one man, he should not entirely relinquish obstetric practice, the second event arousing suspicion that there might be some special disposition existing conducive to the production of this fatal disease. I should so act myself.

As most important in preventing the spread of the disease, it is evident that some efficient and organised system of espionage is imperative.

I have become aware in my short experience that many deaths have occurred through want of knowledge and due appreciation of the gravity of the consequences likely to follow from persistence in midwifery practice, in the vain hope from day to day that the disease will disappear. Ignorant midwives, and young practitioners who may not have been taught to recognise the peculiar features of this special form of disease, are very prone to fall into this error. Now that officers of health are (or ought to be) generally established in every district throughout England, it should be deemed by the Privy Council one of the chief duties of such officers to investigate the true nature of any epidemic of puerperal fever coming to their knowledge, and to consult with, or advise, the propagators of the mischief. A stumbling-block would, I suspect, be often placed in his way by the fact that the most important means of information-the books of the Registrar of Deaths-do not always furnish a true record of the cause of death, when it is puerperal pyæmia. This is no idle statement, but one which I have verified by reference to the returns in this district, when I have found only two deaths returned as from this cause during two months, when I have had satisfactory knowledge of the occurrence of at least eight. The tendency to observe secrecy in such cases is a fact intelligible, and to some extent, perhaps, excusable. From this point of view alone, I regard the late Sanitary Act as a wise measure, calculated to prevent much human suffering, and to save many valuable lives.

When, ten years ago, I enunciated the theory I have expressed above, the proposition did not elicit any discussion. Possibly, it was deemed unworthy even of notice; yet I feel confident that in the future it will be recognised as by no means so improbable as superficially it may appear to be.

There are many occult problems connected with the etiology of disease, which suggest themselves every day, that are not less strange than that now propounded, and yet they meet with favourable consideration. The theory of transmission from extraneous sources, I grant, at first sight would seem most probably true; yet, in the minds of those who may unfortunately have the opportunity that experience affords, I feel certain that grave doubts of its validity will arise.

TuE Ryan Prize, value $f 100$, offered about two years since by the Board of Trinity College for the essay that would produce from the Bible the best argument for the truth or Divine origin of Christianity, has been awarded to a member of the profession, Dr. Isaac Ashe, Medical Superintendent of the Londonderry District Lunatic Asylum. Dr. Ashe obtained the second Carmichael prize, value $£$ roo, in 1868 ; and the first Carmichael prize, value $£ 200$, in 1873 . 